УДК: 316.754

10.17213/2075-2067-2020-6-96-101

\title{
О ВЛИЯНИИ РОССИЙСКОЙ ПРАВОВОЙ КУЛЬТУРЫ НА СОЦИАЛЬНОЕ ПОВЕДЕНИЕ ИНДИВИДОВ
}

\author{
(C) 2020 г. И. А. Петрулевич
}

\section{Южный федеральный университет, г. Ростов-на-Дону, Россия}

Целью исследования является выявление влияния российской правовой культуры на модели соииального поведения индивидов. Правовая культура является одним из главньх внешних регулятивов сочииального поведения, следовательно, ее качественные характеристики и интерпретация индивидами оказывают влияние на выбор модели соичиального поведения.

Методологическую базу исследования представляют теоретико-методологические подходы к изучению сочиального поведения, в частности, институциональная теория, а также результаты эмпирических исследований, посвященных правосознанию россиян и восприятию индивидами правовой культуры общества. Исследование базируется на интерпретации правовой культуры как правового свойства субъектов права.

Результаты исследования. Раскрыты механизмы влияния правовой культуры на выбор индивидами моделей поведения. Выведены две модели поведения, рассматриваемые в контексте правовой культуры: правомерное и внеправовое. Раскрыто понятие внеправового поведения и проведен анализ степени его социальной опасности и сложности выявления подобного поведения. Незнание индивидами своих прав и неумение их отстаивать приводит к осознанному или неосознанному совершению внеправовых действий, интенсифицирующих процесс маргинализации бедных слоев населения и дестабилизирующих социальное пространство.

Перспективу исследования составляет дальнейшее формирование средств повышения правовой грамотности населения и разработка средств эффективного воздействия на их восприятие правовой культуры. Также высоким потенциалом обладает операчионализачия понятия сочииальой справедливости на уровне взаимодействия индивидов и разработки способов по социальному управлению этим явлением.

Ключевые слова: правовая культура; сочиальное поведение; сочиальная инженерия; правосознание; внеправовое поведение; маргинализация; государственное регулирование.

\section{ON THE IMPACT OF RUSSIAN LEGAL CULTURE ON THE SOCIAL BEHAVIOR OF INDIVIDUALS}

\section{(C) 2020 I. A. Petrulevich}

\section{Southern Federal University, Rostov-on-Don, Russia}

The purpose of the study is to identify the impact of Russian legal culture on the models of social behavior of individuals. Legal culture is one of the main external regulators of social behavior, therefore, its qualitative characteristics and the interpretation of its individuals influence the choice of the model of social behavior.

The methodological basis of the research present theoretical and methodological approaches to the study of social behavior institutional theory, as well as the results of empirical research on 
the legal consciousness of Russians and individuals'perception of the legal culture of society. The research is based on the interpretation of legal culture as a legal property of subjects of law.

The results of the research. The mechanisms of influence of legal culture on the choice of individuals' behavioral patterns are revealed. Two models of behavior considered in the context of legal culture: legal and extra-legal. The concept of extra-legal behavior is revealed and the analysis of the degree of its social danger and complexity of revealing such behavior is conducted. Failure of individuals to know their rights and to defend them leads to conscious or unconscious committing extra-legal actions that intensify the process of marginalization of the poor and destabilizing social space.

The prospects for this study are the further development of means of increasing legal literacy of the population and the development of means of effective influence on their perception of legal culture. There is also a high potential for operationalizing the concept of social justice at the level of interaction between individuals and developing methods for social management of this phenomenon.

Key words: legal culture; social behavior; social engineering; legal consciousness; extralegal behavior; marginalization; state regulation.

Введение. Социальное поведение индивида зависит от множества внешних и внутренних факторов, влияющих на принятие того или иного решения, а также выбора тактики и стратегии социальных интеракций. Одним из важнейших элементов совершения социальных действий является соотнесение ожидаемого результата и социальных норм, лежащих во множестве плоскостей. Эти нормы, в свою очередь, связаны с культурой, имеющей многомерное и комплексное строение, разделяемое на различные сферы жизни общества. Правовая культура является одним из важнейших регулятивов социального поведения, так как проводит демаркационную линию между «правовым» и «внеправовым» поведением. Качественные различия правовой культуры разных стран и режимов приводят нас к пониманию того, что результаты действий, которые планируют совершать индивиды, будут интерпретированы ими поразному, а это ведет к необходимости научного осмысления влияния правовой культуры на модели социального поведения граждан.

Методологические основы исследования. Для того чтобы понять, как правовая культура влияет на социальное поведение, необходимо определиться с наиболее релевантным подходом к его изучению. Для этого обратимся к институциональной теории, уде- ляющей внимание рассмотрению внешних регулятивов социального поведения. Ее сущность заключается в том, что социальное поведение является следствием интерпретации социальной ситуации в определенном культурном контексте, задающим традиции, нормы социального поведения и прочие устоявшиеся паттерны социальных взаимодействий, которые индивид считает одобренными и безопасными к исполнению [7.]

Перейдем к рассмотрению правовой культуры и обратимся к интерпретации Бондарева, понимающего ее как правовое свойство субъектов права, т.е. степени их правовой развитости, правового совершенства, уровня их способностей качественно творить и эффективно использовать правовые средства для достижения своих правомерных целей, интересов и потребностей [4]. Из этого следует, что правовая культура неотделима от субъективного восприятия индивидами граней законности и социальной опасности. Иными словами, для каждого индивида понимание права будет зависеть от его правовой грамотности и приверженности к этим нормам. Таким образом, социальное поведение индивидов напрямую связано с интерпретацией социальной ситуации и соотнесением ожидаемого результата планируемых им действий с нормами и правилами, источником которых является правовая культура, являющаяся объектом субъективной интерпретации. 
Результаты исследования. Российская социальная реальность характеризуется размытием множества устоявшихся ценностей и норм, что приводит к неопределенности при выборе тех или иных моделей социального поведения. Социально-экономические перемены, связанные с распадом Советского Союза и переходом к рыночной экономике, заставляют индивида переосмыслить паттерны привычного для него социального поведения и ставят перед необходимостью начать действовать по-другому. Таким образом, социально-экономическая ситуация посткризисной России ставит людей перед необходимостью преодоления состояния экзистенциальной неопределенности и переосмысления моделей социального поведения [3]. В подобном случае невозможно рассчитывать на внутренние регулятивы социального поведения, так как быстро меняющаяся социально-экономическая конъюнктура задает высокий темп общественных изменений, следовательно, заставляет индивидов быстрее адаптироваться к постоянно меняющимся условиям. В такой ситуации внутренние регулятивы уступают приоритетное место внешним. Объясняется это тем, что в устоявшемся обществе стабильность тех или иных социальных практик институционализируется, и их результаты запоминаются индивидами и становятся фундаментом для стратегического и тактического планирования своего социального поведения, однако в обществе, постоянно подвергающемся социальным изменениям, этот фундамент не выстраивается. Это, в свою очередь, выводит внешние регулятивы социального поведения на первый план, так как они нормализованы в тех или иных документах, объективны и применимы ко всем членам общества, то есть не требуют усилий по их интерпретации. Из этого следует, что в ситуации социально-экономической турбулентности именно внешние регулятивы социального поведения должны становиться точкой опоры индивида при принятии тех или иных решений. В этом контексте особо значимое место приобретает правовая культура, так как она является не только объективным разделителем на правовое и внеправовое поведение, но также объясняет индивиду, что есть «хорошо», а что «плохо».

Важной особенностью социального поведения российских граждан является низкая институционализация их повседневных практик, уходящая корнями в Советский Союз, поставивший граждан перед необходимостью решать множество бытовых вопросов вне правового поля [5]. Социальные институты советского режима не успевали за растущими потребностями населения, и из-за этого множество вопросов решалось не институционально, а индивидуально. Исследование, проведенное аналитическим центром НАФИ, показало, что в 2019 году 42\% респондентов предпочитали решать проблемы нарушения их прав путем обращения лично к тем, кто их нарушил, лишь 20\% писали официальные жалобы руководству или в вышестоящие инстанции [2]. Ситуация усугубляется также тем, что $44 \%$ респондентов посчитали, что защита своих прав «ни к чему бы не привела», а $22 \%$ опрошенных сошлись на том, что попытки отстаивать свои интересы в рамках правового поля создали бы еще больше проблем. Результаты этого исследования подтверждают наше предположение о том, что современные россияне не доверяют устоявшимся социальным институтам и зачастую решают те или иные проблемы вне правового поля. Эта особенность перекочевала из советского режима и сопряжена с большим количеством социальных рисков. Они заключаются в неумении индивидов четко разделять правомерные и неправомерные действия, что объясняется их низким правосознанием. Самооценка среднестатистического жителя региона согласно социальному опросу, проведенному в Тюменской области, находится примерно на среднем уровне, что говорит о том, что он знает отдельные нормативно-правовые акты, но не умеет их применять [1]. При этом высоко оценивают свою правовую грамотность лишь 16\% респондентов, низкую оценку выбрали $18 \%$ опрошенных, а 74\% респондентов не знают, куда следует обращаться в случае нарушения их гражданских прав. Исходя из этих результатов, можно заключить следующее: недостаточное понимание людьми правовой культуры своей страны приводит к тому, что они осознанно или неосознанно совершают внеправовые действия. Стоит отметить, что внеправовые действия не всегда равны противоправным (общественно-опасным) и во множестве случаев не окажут серьезно- 
го отрицательного влияния на общественное пространство в краткосрочной перспективе, но могут оказать отрицательное влияние на общественное сознание в долгосрочной перспективе. Таким образом, современная правовая культура России разделяет модели поведения людей на две группы:

- правомерное - общественно полезное, необходимое и желанное поведение, которое обеспечивает организованность и гармоничность общественной жизни, а также поддерживает устойчивый правопорядок;

- внеправовое - лежащее за гранью правового поля, но не воспринимаемое субъектом как правонарушение.

Как видно из вышеприведенных моделей, правомерное действие является социально-полезным и одобренным обществом оно не несет в себе каких-либо рисков, так как является устойчивым и легко воспроизводимым множеством индивидов. Иными словами, правомерное поведение находится под влиянием того или иного социального института, следовательно, индивид подчиняется институциональным правилам игры. Внеправовое поведение синонимично «теневому» и имеет множество граней различной степени социальной опасности. Оно характеризуется тем, что индивид осознанно выбирает именно такой тип поведения, так как он может удовлетворить его потребности в наиболее полном виде, в отличие от правомерного. Принимая решение следовать внеправовому поведению, индивид соотносит желаемые результаты с социальной ситуацией и оглядывается на правовую культуру общества. Это приводит нас к следующему выводу: правовая культура имеет проблемы на двух уровнях - объективном и субъективном. Объективный уровень правовой культуры связан с умением государственных институтов поддерживать социально-желаемые модели поведения и контролировать их исполнение. Субъективный же уровень связан с интерпретацией индивидами понятий законности и правовой грамотностью населения. В случае, если индивид не знает того, какая модель поведения является правомерной, существует вероятность, что он поступит неправильно из-за собственного незнания. При этом он может выбрать внеправовое или противоправное поведение осознанно из-за того, что не воспринимает определенные элементы правовой культуры как важные [6].

Идеальной иллюстрацией осознанного выполнения внеправовых действий является покупка россиянами пиратской (нелицензионной) продукции. Современные российские законы трактуют ее продажу и покупку как противоправную, однако в сознании россиян отсутствует исторически обоснованное уважение к правам на интеллектуальную собственность. Если добавить к этому отсутствие серьезных санкций за приобретение пиратских продуктов, то можно сделать вывод о том, что в правовой культуре имеется своеобразная лакуна, не позволяющая населению сформировать правильное понимание вопроса законности покупки этой продукции. Вышеописанный пример демонстрирует взаимосвязь объективного и субъективного уровня правовой культуры, так как власть не может обеспечить серьезный контроль социального поведения людей, а они, в свою очередь, не разделяя ценности тех или иных прав, преступают закон.

Таким образом, правовая культура современной России складывается из двух элементов: законов и нормативных актов (объективный уровень) и субъективного восприятия этих норм индивидами (субъективный уровень). Она оказывает непосредственное влияние на социальное поведение граждан и зачастую определяет, какое социальное действие совершит индивид. Социальное поведение человека устроено таким образом, что он за очень короткое время соотносит предполагаемые результаты своих действий со множеством внутренних и внешних регулятивов, оказывающих влияние на окончательный выбор той или иной тактики своих действий. Как говорилось ранее, в обществах, характеризующихся экономической неопределенностью, неуверенностью в завтрашнем дне и низкой социальной защищенностью, наиболее важное значение будут иметь именно внешние регулятивы, то есть законы, нормы и правила. Именно по этой причине низкая правовая культура может повлечь за собой маргинализацию бедных слоев населения и распространение девиантного поведения. Аналогичные риски можно найти и в экономической сфере жизни общества, так как низкая степень ответственности людей за свои 
поступки способствует расширению «серой» зоны экономики.

Заключение. Резюмируя все вышесказанное, можно сказать, что российская правовая культура требует серьезной работы как на объективном, так и на субъективном уровне. Исправление ошибок на первом уровне должно быть инициировано законодателем и начинаться, как минимум, с экстенсивных мероприятий по толкованию населению важности тех или иных законов и норм. На субъективном уровне подобная работа возможна лишь с привлечением общественных организаций и прочих гражданских ресурсов, ориентированных на повышение правосознания россиян с использованием горизонтальных каналов коммуникации.

\section{Литература}

1. Акулич М.М., Пить В.В. Правовая культура населения как фактор социальной стабильности // Вестник РУДН. Серия: Социология. - 2015. - №1.

2. Россияне охотнее отстаивают свои права в теории, чем на практике [Электронный pecypc] // Аналитический центр НАФИ. Режим доступа: https:/nafi.ru/analytics/ rossiyane-okhotnee-otstaivayut-svoi-pravav-teorii-chem-na-praktike-en-russians-morewillingly-defen/.

3. Багаутдинов Р.А. Сущность и причины неопределенности в экономике России // ВЭПС. - 2008. - №6.

4. Бондарев А. С. Правовая культура общества: проблемы понятия и структуры // Вестник Пермского университета. Юридические науки. - 2014. - №4 (26).

5. Завалев A. B. Постсоветская аномия общества // Власть. - 2012. - №5.

6. Ковалев B. B. Социальные стереотипы как образующая основа особенностей правового сознания российского общества // Философия права. - 2008. - №3.
7. Лубский А. В., Чернобровкина Н. И. Модели социального поведения и формы социального контроля в России // Социально-гуманитарные знания. — 2017. — №7.

\section{References}

1. Akulich M.M., Pit' V.V. Pravovaja kul'tura naselenija kak faktor social'noj stabil'nosti [Legal culture of the population as a factor of social stability] // Vestnik RUDN. Serija: Sociologija [RUDN Bulletin. Series: Sociology]. — 2015. — №1.

2. Rossijane ohotnee otstaivajut svoi prava $\mathrm{v}$ teorii, chem na praktike [Russians are more willing to defend their rights in theory than in practice] [Jelektronnyj resurs] // Analiticheskij centr NAFI [NAFI analytical center]. — URL: https://nafi.ru/analytics/rossiyane-okhotnee-otstaivayut-svoi-prava-v-teorii-chem-na-praktikeen-russians-more-willingly-defen/.

3. Bagautdinov R. A. Sushhnost' i prichiny neopredelennosti v jekonomike Rossii [The essence and causes of uncertainty in the Russian economy] // VJePS. — 2008. — №6.

4. Bondarev A.S. Pravovaja kul'tura obshhestva: problemy ponjatija i struktury [Legal culture of a society: problems of the notion and structure] // Vestnik Permskogo universiteta. Juridicheskie nauki [Vestnik of Perm University. Legal science]. — 2014. — №4 (26).

5. Zavalev A. V. Postsovetskaja anomija obshhestva [Post-Soviet anomie of society] // Vlast' [Power]. — 2012. — №5.

6. Kovalev V.V. Social'nye stereotipy kak obrazujushhaja osnova osobennostej pravovogo soznanija rossijskogo obshhestva [Social stereotypes as forming the basis of the features of the legal consciousness of the Russian society] // Filosofija prava [Philosophy of law]. — 2008. - №3.

7. Lubskij A.V., Chernobrovkina N.I. Modeli social'nogo povedenija i formy social'nogo kontrolja $\mathrm{v}$ Rossii [Models of social behavior and forms of social control in Russia] // Social'nogumanitarnye znanija [Social and humanitarian knowledge]. — 2017. — №7. 


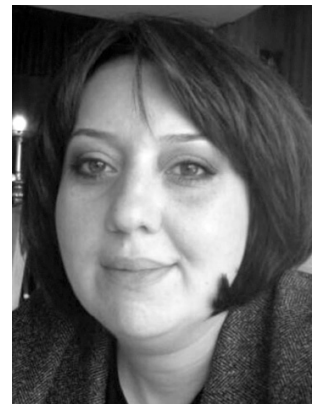

Петрулевич Ирина Анатольевна - доктор социологических наук, профессор Института истории и международных отношений Южного федерального университета.

Petrulevich Irina Anatolyevna - Doctor of Sociological Sciences, Professor, Institute of History and International Relations, Southern Federal University.

344006, г. Ростов-на-Дону, ул. Б. Садовая, 105/42

105/42 B. Sadovaya st., 344006, Rostov-on-Don, Russia

E-mail: iapetrulevich@sfedu.ru 